\title{
Cardiovascular magnetic resonance of pulmonary artery growth and ventricular function after Norwood procedure with Sano modification
}

\author{
D Scott Lim*1, Benjamin B Peeler ${ }^{2}$, G Paul Matherne ${ }^{1}$ and \\ Christopher M Kramer ${ }^{3}$
}

Address: ${ }^{1}$ Department of Pediatrics, University of Virginia, Charlottesville, USA, ${ }^{2}$ Department of Surgery, University of Virginia, Charlottesville, USA and ${ }^{3}$ Departments of Medicine \& Radiology, University of Virginia, Charlottesville, USA

Email: D Scott Lim* - SL9PC@virginia.edu; Benjamin B Peeler - BBP2T@virginia.edu; G Paul Matherne - GPM2Y@virginia.edu; Christopher M Kramer - CMK2N@virginia.edu

* Corresponding author

Published: 6 July 2008

Journal of Cardiovascular Magnetic Resonance 2008, 10:34 doi:10.1 I86/I532-429X-1034

This article is available from: http://www.jcmr-online.com/content//0/I/34

(C) 2008 Lim et al; licensee BioMed Central Ltd.

This is an Open Access article distributed under the terms of the Creative Commons Attribution License (http://creativecommons.org/licenses/by/2.0), which permits unrestricted use, distribution, and reproduction in any medium, provided the original work is properly cited.
Received: 25 March 2008

Accepted: 6 July 2008

\begin{abstract}
For hypoplastic left heart syndrome (HLHS), there have been concerns regarding pulmonary artery growth and ventricular dysfunction after first stage surgery consisting of the Norwood procedure modified with a right ventricle-to-pulmonary artery conduit. We report our experience using cardiovascular magnetic resonance (CMR) to determine and follow pulmonary arterial growth and ventricular function in this cohort.

Following first stage palliation, serial CMR was performed at I and 10 weeks post-operatively, followed by cardiac catheterization at $4-6$ months. Thirty-four of 47 consecutive patients with HLHS (or its variations) underwent first stage palliation. Serial CMR was performed in 20 patients. Between studies, ejection fraction decreased ( $58 \pm 9 \%$ vs. $50 \pm 5 \%, p<0.05)$. Pulmonary artery growth occurred on the left $(6 \pm I \mathrm{~mm}$ vs. $4 \pm \mathrm{I} \mathrm{mm}$ at baseline, $p<0.05)$ but not significantly in the right. This trend continued to cardiac catheterization 4-6 months post surgery, with the left pulmonary artery of greater size than the right $(8.8 \pm 2.2 \mathrm{~mm}$ vs. $6.7+/-1.9 \mathrm{~mm}, \mathrm{p}<0.05)$. By CMR, 5 had pulmonary artery stenoses initially, and at 2 months, 9 had stenoses. Three of the 9 underwent percutaneous intervention prior to the second stage procedure.

In this cohort, reasonable growth of pulmonary arteries occurred following first stage palliation with this modification, although that growth was preferential to the left. Serial studies demonstrate worsening of ventricular function for the cohort. CMR was instrumental for detecting pulmonary artery stenosis and right ventricular dysfunction.
\end{abstract}

\section{Background}

Hypoplastic left heart syndrome is a congenital cardiac malformation involving hypoplasia of the ascending aorta, aortic valve atresia or stenosis, a hypoplastic left ventricle, and mitral atresia or hypoplasia[1]. Until the past few years, the standard surgical approach to hypoplastic left heart syndrome has either been a staged surgical palliation, with the first step being the modified 
Norwood procedure[2], or cardiac transplantation[3,4]. The first stage surgical palliation involves aortic arch augmentation, atrial septectomy, and an aorto-pulmonary shunt for pulmonary blood flow. While surgical survival has improved at many institutions, the overall surgical mortality of this first stage of palliation remains significant $[5,6]$. Recently, a large number of institutions (including the University of Virginia) have switched to the "Sano" modification of the Norwood procedure, with improved short-term results in some, but not all centers[7,8]. This "Sano" modification of the Norwood procedure uses a valveless right ventricle-to-pulmonary artery conduit in place of the aorto-pulmonary shunt for pulmonary blood flow. However, concern remains regarding the growth of the pulmonary arteries and right ventricular function with this surgical modification, which involves a ventriculotomy in the systemic right ventricle[9]. While echocardiography has become the primary imaging modality in pediatric cardiology, it is limited in its ability to image the branch pulmonary arteries after this surgical intervention.

At the University of Virginia, because of these concerns it became our clinical practice to perform a cardiovascular magnetic resonance (CMR) study prior to discharge and at two months of age, followed by cardiac catheterization at $4-6$ months of age, in children with hypoplastic left heart syndrome. The next stage of surgical palliation was usu- ally performed after $4-6$ months of age, and involved ligation and division of the right ventricle-to-pulmonary artery conduit, and creation of a superior vena cava-topulmonary artery anastomosis. If CMR defined any significant pulmonary artery stenosis or coarctation, earlier transcatheter intervention was undertaken.

The intent of this study was to report on the CMR assessment of growth of the pulmonary arteries and right ventricular function after the Norwood procedure with Sano modification for hypoplastic left heart syndrome.

\section{Methods}

Approval for the study was obtained from the University of Virginia Institutional Review Board Human Investigations Committee. We retrospectively reviewed the results of all children admitted following birth to the University of Virginia with the diagnosis of hypoplastic left heart syndrome (or its variations) from 2002 to the end of 2006. The time period was chosen because in mid-2002 our institution switched from the "standard" modified Norwood procedure $[2,10]$ to the Sano modification $[8,11]$. (Figure 1) The procedure was carried out with arterial cannulation via the innominate artery and regional perfusion with minimal use of deep hyperthermic circulatory arrest. The neoaortic arch was constructed utilizing pulmonary homograft. The right ventricular to pulmonary artery con-

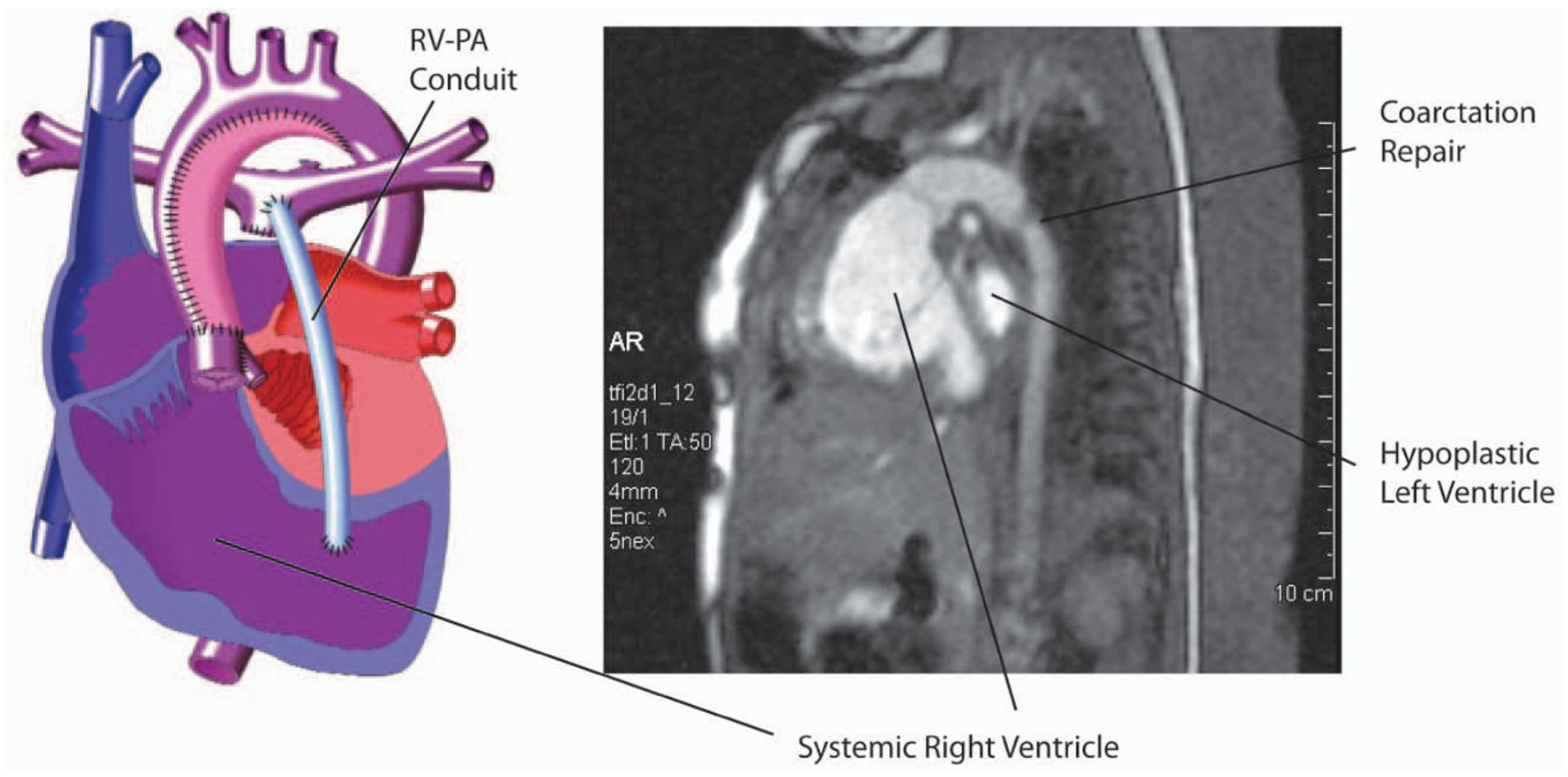

Figure I

Left-sided drawing demonstrates surgical anatomy after Norwood procedure with Sano modification, in which pulmonary blood flow is supplied by right ventricle-pulmonary artery conduit as labeled. Right-sided CMR image shows site of coarctation repair and systemic right ventricle. (Drawing reprinted with permission from Scientific Software Solutions, Inc.) 
duit was constructed using either 5 or $6 \mathrm{~mm}$ ringed polytetrafluoroethylene graft, running to the patient's right of the neoaorta, and a chimney patch created and anastomosed to the confluence of pulmonary arteries distally. The chimney patch was constructed using a $0.4 \mathrm{~mm}$ thin polytetrafluoroethylene cardiovascular patch and the ringed polytetrafluoroethylene conduit. The polytetrafluoroethylene patch was cut into an elliptical shape, and a $6 \mathrm{~mm}$ hole was created in the center of the patch using an aortic punch. The conduit was anastamosed to the opening in the patch using a 6-0 prolene suture, and the chimney patch was then anastamosed to the pulmonary artery confluence. A $4.8 \mathrm{~mm}$ aortic punch was used to create a ventriculotomy in the right ventricular outflow tract. This right ventriculotomy is used for the proximal anastomotic site for the right ventricle-to-pulmonary artery conduit. The conduit size was $5 \mathrm{~mm}$ in patients $<3.5 \mathrm{~kg}$, and $6 \mathrm{~mm}$ in the remainder. The same surgical and cardiology team was involved in all cases.

Following an episode of unrecognized conduit and pulmonary artery stenosis leading to cardiovascular collapse, we began a clinical program of surveillance screening by CMR for the development of significant pulmonary artery stenosis or coarctation of the aorta. CMR was performed in patients prior to discharge after first stage surgery, and again at 2 months post-operatively. By prospective protocol, CMR was also performed at 1 year of age in patients with persistent late ventricular dysfunction as defined by follow-up echocardiography.

Studies were performed with general anesthesia and endotracheal intubation, which allowed the patients to remain still for the studies. Cardiac CMR was performed on a 1.5 Tesla Sonata scanner (Siemens Medical Solutions, Erlangen, Germany). The patient was placed supine in a two-channel head coil with monitoring of electrocardiogram, blood pressure, and oxygen saturation. Steady state free precession (SSFP) cine imaging was performed with repetition time of $2.7 \mathrm{~ms}$, echo time $1.3 \mathrm{~ms}$, temporal resolution $19 \mathrm{~ms}$, slice thickness $4 \mathrm{~mm}$, flip angle $27^{\circ}$, field of view $200 \mathrm{~mm}$, matrix $76 \times 192$, and 4-5 signal averages during free breathing. Spatial resolution for SSFP was $2.6 \times 1.0 \times 4.0 \mathrm{~mm}$. Axial and right ventricular shortaxis image stacks were obtained without a gap. In addition, velocity encoded gradient echo cine imaging was obtained perpendicular to the proximal portion of the right ventricle-to-pulmonary artery conduit and in the plane of the proximal branch pulmonary arteries with repetition time of $4 \mathrm{~ms}$, echo time of $3.6 \mathrm{~ms}$, temporal resolution of $29 \mathrm{~ms}$, slice thickness $4 \mathrm{~mm}$, flip angle $30^{\circ}$, field of view $200 \mathrm{~mm}$, matrix $93 \times 256$, velocity encoded at 300 $\mathrm{cm} / \mathrm{s}$, and 3 signal averages during free breathing. Spatial resolution for velocity encoded images was $2.2 \times 0.8 \times 4.0$ $\mathrm{mm}$. Finally, a 3-dimensional contrast-enhanced CMR angiogram was obtained during infusion of $0.2 \mathrm{mM} / \mathrm{kg}$ of gadolinium-DTPA. The angiogram was obtained in $1 \mathrm{slab}$ with repetition time of 3.75 , echo time $1.4 \mathrm{~ms}$, slice thickness of $0.9 \mathrm{~mm}$, flip angle $30^{\circ}$, field of view $200 \mathrm{~mm}$, matrix $75 \times 320$, and 6 signal averages. Spatial resolution for CMR angiogram images was $2.7 \times 0.6 \times 0.9 \mathrm{~mm}$.

Dedicated analysis software (Argus, Siemens Medical Solutions, Malvern, PA) was utilized to calculate enddiastolic ventricular volumes and systolic function from the short axis SSFP cine images. The anterior-posterior diameter of the branch pulmonary arteries was measured from the velocity encoded cine images and confirmed by the CMR angiogram, and the point of measurement was at the hilum. SSFP cine images were not used for this measurement because of off-resonance flow effects that prevented adequate visualization of the branch pulmonary arteries. Significant pulmonary artery stenosis or coarctation were defined by CMR as an abrupt luminal narrowing $>40 \%[12]$. Right ventricle-to-pulmonary artery conduit regurgitation volume and fraction was measured from the velocity encoded imaging obtained perpendicular to the conduit using Argus software. The CMR angiogram was viewed on the Argus 3-dimensional workstation as a multiplanar reformat and maximum intensity projection.

At time of CMR, all patients also had transthoracic echocardiography to compare estimates of ventricular function, and diagnoses of pulmonary artery stenoses and aortic coarctation. (Figure 2) Pulmonary artery stenosis was diagnosed by demonstrating a qualitative luminal narrowing on the color Doppler signal, rather than by Doppler-derived gradients as there were high velocities from the proximal conduit. Two-dimensional imaging by echocardiography was not able to evaluate the branch pulmonary artery anatomy after surgical palliation with the right ventricle-pulmonary artery conduit. Echocardiographic definition of coarctation was a peak-instantaneous Doppler-derived gradient in the aorta of $>20 \mathrm{mmHg}$ using both proximal and distal velocities in the complete modified Bernoulli equation [13].

All patients underwent cardiac catheterization prior to the second stage surgery, which was intended at 4-6 months of age. Right ventricular ejection fraction was calculated by calibrated biplane Simpson's rule [14]. Given the difficulty with interpretation of multiple pressure gradients in series, and that a large gradient is normally present across the right ventricle-pulmonary artery conduit, only the presence of a gradient at the site of angiographic luminal narrowing in the branch pulmonary artery was used to define a significant pulmonary artery stenosis. A significant coarctation was defined by catheterization as a gradient of $>20 \mathrm{mmHg}$ in the presence of angiographic 


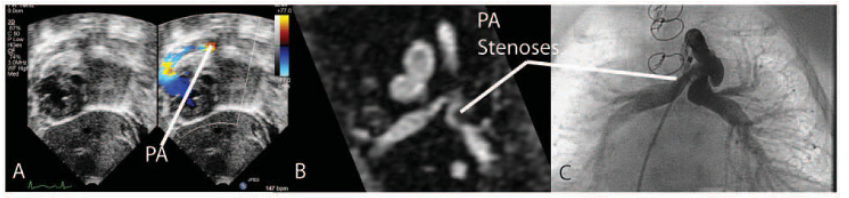

Figure 2

Panel A illustrates the difficulty in imaging the branch pulmonary arteries by transthoracic echocardiography. Turbulence from the normally increased flow across the right ventricle-pulmonary artery conduit obscures the branch pulmonary artery anatomy. Panel B is in the same patient and branch pulmonary artery stenoses are demonstrated clearly by CMR, which is confirmed at time of cardiac catheterization and angiography in panel $\mathrm{C}$.

narrowing[15]. Significant coarctations underwent percutaneous balloon angioplasty[16,17], and success was defined as a gradient of $<10 \mathrm{mmHg}$ without significant drop in cardiac output.

The authors had full access to the data and take responsibility for its integrity. All authors have read and agree to the manuscript as written.

\section{Statistical Analysis}

Serial measurements for patients were compared using analysis of variance for repeated measures, and comparison between patients was analyzed using unpaired $t$ tests, with statistical significance defined as $\mathrm{p}<0.05$.

\section{Results \\ Demographics}

From 2002 to 2006, 47 newborns with hypoplastic left heart syndrome (or its variations, see Table 1) were admitted to the University of Virginia. Six patients received palliative care only and expired shortly thereafter. Seven patients with HLHS and high-risk features underwent hybrid palliation, and have been previously reported on by our group[18]. The remaining 34 patients underwent the Norwood procedure with Sano modification at an age of $9+/-8$ days (range 1 - 47 days), with survival to hospital discharge in 26 of 34 . Initially, the first 9 infants underwent surgical intervention, and the 6 survivors were followed without CMR screening. Following these first 9

Table I: Anatomic diagnoses of the cohort are listed.

\begin{tabular}{lc}
\hline Anatomic Diagnoses & n \\
\hline Hypoplastic left heart syndrome & 30 \\
Heterotaxy/Unbalanced AV canal with left ventricular hypoplasia & 3 \\
Double outlet right ventricle with left ventricular hypoplasia & I
\end{tabular}

patients, we then began the CMR screening program for the reasons noted above. For the remainder of the study period 25 infants underwent surgical palliation, of which 5 patients expired prior to hospital discharge, with cardiac CMR being performed in the remaining 20 patients. There were no complications from the anesthesia for the CMR study.

\section{CMR evaluation of the right ventricle}

From the initial pre-discharge CMR study to the 2-month study, right ventricular volumes increased $(19 \pm 6 \mathrm{~mL}$ vs. $32 \pm 5 \mathrm{~mL}, \mathrm{p}<0.05)$ but were not different compared with body growth $\left(102 \pm 33 \mathrm{~mL} / \mathrm{m}^{2}\right.$ vs. $105 \pm 33 \mathrm{~mL} / \mathrm{m}^{2}, \mathrm{p}=$ NS), and right ventricular ejection fraction decreased $(58.0 \pm 8.9 \%$ vs. $49.9 \pm 5.4 \%, p<0.05)$. (Figure 3$)$ The right ventricular ejection fraction as seen on the cardiac catheterization prior to the $2^{\text {nd }}$ stage surgical palliation was $45 \pm 9 \%$. A comparison between echocardiographic and CMR estimates of right ventricular function is shown in Figure 4. There is overlap in CMR-determined right ventricular ejection fraction between the different echocardiographic classifications of ventricular function. The CMRdetermined right ventricular ejection fraction in the group with "good" systolic function by echocardiography was 53 $\pm 8 \%$, with $25 \pm 11 \%$ in the moderate group. The single patient with an echocardiographic estimate of "poor" function had an ejection fraction of $16 \%$.

\section{CMR evaluation of the branch pulmonary arteries}

At time of initial CMR, the right and left pulmonary arteries were of similar size $(4.6 \pm 0.9 \mathrm{~mm}$ vs. $4.4 \pm 1.0 \mathrm{~mm}, \mathrm{p}$ $=$ NS). However, pulmonary artery growth occurred mainly in the left pulmonary artery $(6.3 \pm 1.1 \mathrm{~mm}$ vs.4.4 $\pm 1.0 \mathrm{~mm}$ at baseline, $\mathrm{p}<0.05)$, but not significantly in the right $(5.2 \pm 1.5 \mathrm{~mm}$ vs. $4.6 \pm 0.9 \mathrm{~mm}$ at baseline, $\mathrm{p}=$ NS), with the left pulmonary artery larger at time of the $2^{\text {nd }}$ CMR $(6.3 \pm 1.1 \mathrm{~mm}$ vs. $5.2 \pm 1.5 \mathrm{~mm}$ for the right pulmonary artery, $\mathrm{p}<0.05$ ). (Figures 5 \&6) This trend appeared to continue to the cardiac catheterization at $4+/$ - 1 months post surgery, with the left pulmonary artery of significantly greater size than the right $(8.8 \pm 2.8 \mathrm{~mm}$ vs $6.7 \pm 1.9 \mathrm{~mm}$ for the right pulmonary artery, $\mathrm{p}<0.05)$.

By CMR, 5 patients had pulmonary artery stenoses defined at the two-week study, and at the two-month study $9 / 20$ had pulmonary artery stenoses. Three of these underwent early percutaneous intervention for severe unilateral stenoses. On all 9 patients with CMR-defined pulmonary artery stenosis, cardiac catheterization confirmed the diagnosis. In those patients without CMR-defined pulmonary artery stenosis, no significant pulmonary artery stenosis was found at time of pre-operative cardiac catheterization. 


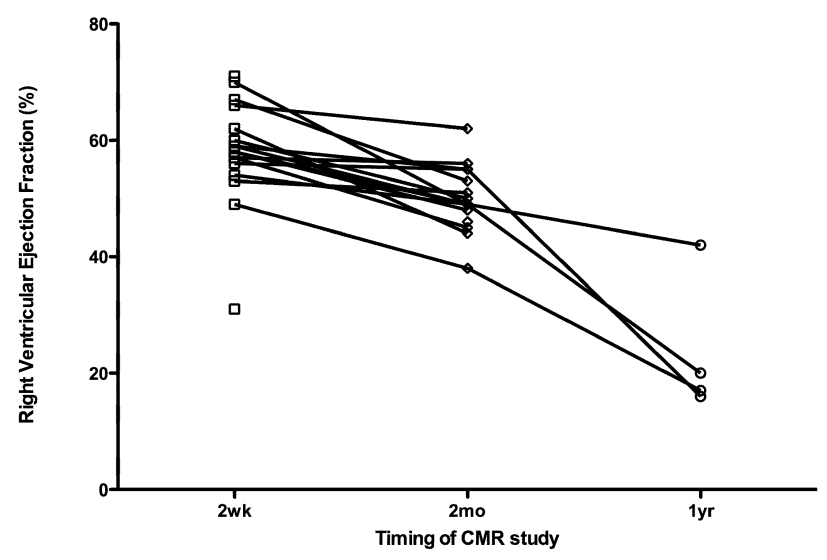

Figure 3

Serial measurement of right ventricular ejection fraction is shown, as assessed by cardiac CMR.

However, the ability of echocardiography to diagnose CMR-diagnosed pulmonary artery stenosis was poor, with only a $6 \%$ sensitivity ( 1 of 18 stenoses were diagnosed by echocardiography). There were no false positive diagnoses of pulmonary artery stenosis by echocardiography.

There was no significant change in conduit regurgitant fraction ( $15 \pm 4 \%$ vs. $16 \pm 5 \%)$ between studies.

\section{CMR evaluation of the aortic coarctation}

While 9 patients were defined by CMR at the 2-week study as having a coarctation, clinically it was determined that these did not require reintervention at that time. Among

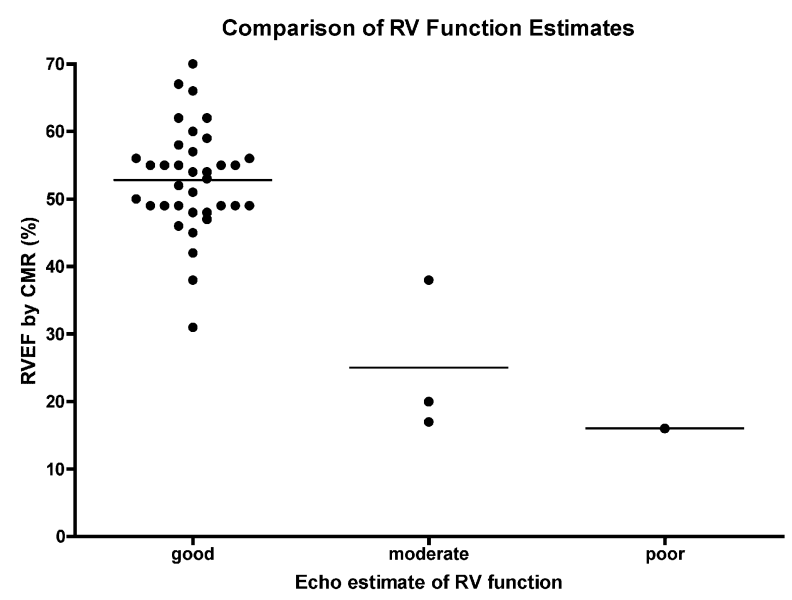

Figure 4

Comparison between echocardiographic and cardiac magnetic resonance imaging assessments of right ventricular systolic function is shown.

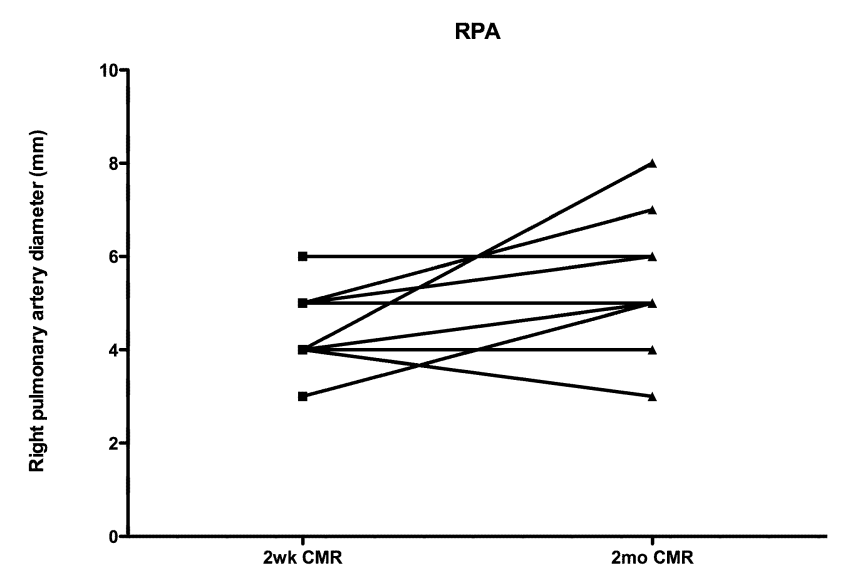

Figure 5

Growth in the right pulmonary artery is shown.

these 9 patients, coarctations in 6 persisted or worsened by the 2-month study, and resolved in 3. 2 additional patients developed a significant coarctation that was defined on the 2-month study. Ten of the $261^{\text {st }}$ stage survivors underwent percutaneous coarctation intervention, which was judged successful in 7 , and one was felt not to have clinical coarctation despite the CMR findings. This was related to an artifact caused by a metal surgical clip. Of the patients not diagnosed by CMR with a coarctation, one was found to have a coarctation at time of the preoperative cardiac catheterization.

Echocardiography agreed with CMR-diagnosed coarctation in 7 of 10 patients who underwent cardiac catheterization. A single patient erroneously diagnosed with a

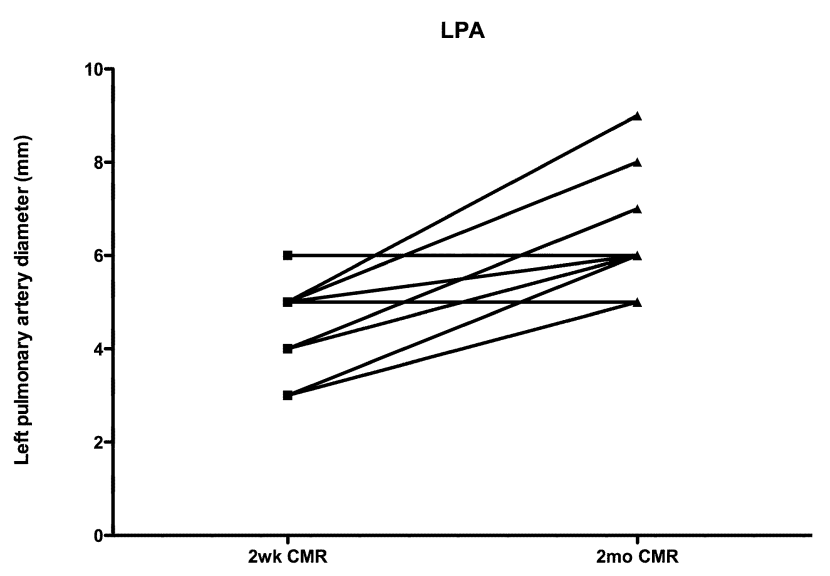

Figure 6

Growth of the left pulmonary artery is shown. There was significant growth between the first and second CMR studies. 
coarctation by CMR was thought not to have a significant gradient by Doppler, and two unsedated patients did not have adequate arch views to determine the presence of coarctation by echocardiography.

Those patients not having a diagnosis of recurrent coarctation had a right ventricular ejection fraction by CMR of $48+/-8 \%$ as compared to those with recurrent coarctation their ejection fraction was $41+/-12 \%(\mathrm{p}=\mathrm{NS})$.

\section{Discussion}

In this cohort of patients, CMR demonstrates an important role in the detection of surgical issues complicating the Norwood procedure with Sano modification. It was able to define pulmonary artery stenosis with $100 \%$ sensitivity and specificity, and has already been proven to be instrumental in the evaluation of right ventricular function and aortic coarctation.

Pulmonary artery growth in this cohort of infants with hypoplastic left heart syndrome after the Norwood procedure with Sano modification was asymmetric, with greater growth in the left pulmonary than the right. This asymmetry of growth may be related to both the direction of the flow from the right ventricle-to-pulmonary artery conduit, which is preferential to the left pulmonary artery, and that the right pulmonary artery must then pass under the reconstructed aortic arch. This is in contrast to the standard Norwood palliation, which involves a modified Blalock Taussig shunt, which frequently comes off of the right-sided innominate artery and inserts onto the right pulmonary artery. Previous work has shown asymmetric growth of the pulmonary arteries after the right-sided modified Blalock Taussig shunt, with the right pulmonary artery larger than the left [19]. In either type of surgical shunt, pulmonary artery asymmetry of growth may have important late implications which have not been yet defined.

For diagnosing recurrent or persistent coarctation of the aorta, the CMR has been described as highly sensitive and specific $[12,20]$. However, in 1 patient, the CMR incorrectly gave a suspicion of a coarctation, and in that patient the clinical diagnosis was confounded by femoral arterial occlusion. The patient had been referred for early cardiac catheterization, which determined no gradient across the aortic arch which was widely patent on angiography. Retrospective review found a surgical clip casting an artifact obscuring the aortic isthmus. It is possible that the use of a phase contrast velocity encoding sequence through the area of concern for coarctation may be useful in clarifying this. Therefore, we believe that in the absence of such imaging artifacts, CMR has an excellent ability to define the pulmonary artery and aortic anatomy after the Norwood procedure with Sano modification. However, in our patient series, there was one patient incorrectly diagnosed with coarctation by CMR. In that patient, an aortic luminal narrowing was seen on CMR. Since cuff blood pressures and Doppler echocardiography demonstrated no gradient across the coarctation site, this was felt to be hemodynamically insignificant. This is likely related to the observation that not all anatomic narrowings will produce significant hemodynamic obstructions, which may be ameliorated by vessel wall compliance and presence of collateral vessels.

In this cohort of patients, in which the single ventricle is of right ventricular morphology and in which a ventriculotomy was performed, there was a significant depression of systolic function, as measured by serial study. In addition, out of 26 initial hospital survivors, 2 subsequently underwent cardiac transplantation with another currently being listed. The indication in all 3 such patients was symptomatic heart failure. It is possible that the ventriculotomy plays a role in the development of late ventricular dysfunction, as has been noted in other centers [21]. It is also possible that recurrence of coarctation, with its attendant increased afterload on the right ventricle, may contribute to ventricular dysfunction. In our cohort of patients, we found a non-significant trend of increased ventricular dysfunction in the group with recurrent coarctation. Importantly, we took an approach of early percutaneous intervention to any new diagnosis of recurrent coarctation, on the assumption that the afterload reduction was important in these patients' management.

Both the survival to discharge and the interstage mortality in this cohort of patients following the Norwood procedure with Sano modification were similar to other reports in the current era[5,8,10,22,23], and has been associated with improved peri-operative hemodynamic stability[9]. However, it may be that this is a trade-off for later ventricular dysfunction.

Limitations of the present study include the different imaging modalities to evaluate right ventricular, pulmonary artery, and aortic anatomy and function. However, previous work has demonstrated excellent correlation between CMR and cardiac catheterization for right ventricular volumes and function[24,25], for pulmonary artery anatomy[26], and for coarctation evaluation[27].

\section{Conclusion}

Development of significant pulmonary artery stenosis, coarctation, and right ventricular dysfunction occurs in a portion of patients undergoing the Norwood palliation with Sano modification for hypoplastic left heart syndrome. Cardiovascular magnetic resonance is instrumental in surveillance for such complications. 


\section{Abbreviations}

HLHS: Hypoplastic left heart syndrome; CMR: Cardiac magnetic resonance imaging.

\section{Competing interests}

DSL, BBP, and GPM have no conflicts of interest to disclose. CMK has research equipment support from Siemens Medical.

\section{Authors' contributions}

DSL designed the study, collected data, and drafted the manuscript. BBP performed the surgeries and drafted a portion of the manuscript. GPM participated in study design and data collection. CMK participated in study design and data collection, and drafted a portion of the manuscript. All authors read and approved the final manuscript.

\section{Acknowledgements}

The authors would like to acknowledge Carol Tatum, R.N., for her significant efforts in facilitating the coordination of these patients' imaging studies.

\section{References}

I. Noonan JA, Nadas AS: The hypoplastic left heart syndrome; an analysis of 101 cases. Pediatr Clin North Am 1958, 5(4): 1029-56.

2. Norwood WI, Lang P, Hansen DD: Physiologic repair of aortic atresia-hypoplastic left heart syndrome. N Engl J Med I983, 308(I):23-6.

3. Bailey LL, Nehlsen-Cannarella SL, Doroshow RW, Jacobson JG, Martin RD, Allard MW, Hyde MR, Dang Bui RH, Petry EL: Cardiac allotransplantation in newborns as therapy for hypoplastic left heart syndrome. N Engl J Med 1986, 3 I 5( I 5):949-5I.

4. Razzouk AJ, Chinnock RE, Gundry SR, Johnston JK, Larsen RL, Baum MF, Mulla NF, Bailey LL: Transplantation as a primary treatment for hypoplastic left heart syndrome: intermediateterm results. Ann Thorac Surg 1996, 62(I): 1-7. discussion 8.

5. Gutgesell HP, Gibson J: Management of hypoplastic left heart syndrome in the 1990s. Am J Cardiol 2002, 89(7):842-6.

6. Gutgesell HP, Massaro TA: Management of hypoplastic left heart syndrome in a consortium of university hospitals. Am J Cardiol 1995, 76(I I):809-II.

7. Pizarro C, Malec E, Maher KO, Januszewska K, Gidding SS, Murdison $K A$, Baffa JM, Norwood WI: Right ventricle to pulmonary artery conduit improves outcome after stage I Norwood for hypoplastic left heart syndrome. Circulation 2003, I08(Suppl I):III 55-60.

8. Sano $\mathrm{S}$, Ishino $\mathrm{K}$, Kado $\mathrm{H}$, Shiokawa $\mathrm{Y}$, Sakamoto $\mathrm{K}$, Yokota $M$, Kawada $M$ : Outcome of right ventricle-to-pulmonary artery shunt in first-stage palliation of hypoplastic left heart syndrome: a multi-institutional study. Ann Thorac Surg 2004, 78(6): 1951-7. discussion 1957-8.

9. Maher KO, Pizarro C, Gidding SS, Januszewska K, Malec E, Norwood WI Jr, Murphy JD: Hemodynamic profile after the Norwood procedure with right ventricle to pulmonary artery conduit. Circulation 2003, I 08(7):782-4.

10. Bove EL, Lloyd TR: Staged reconstruction for hypoplastic left heart syndrome. Contemporary results. Ann Surg 1996, 224(3):387-94. discussion 394-5.

II. Sano S, Ishino K, Kawada M, Arai S, Kasahara S, Asai T, Masuda Z, Takeuchi M, Ohtsuki S: Right ventricle-pulmonary artery shunt in first-stage palliation of hypoplastic left heart syndrome. J Thorac Cardiovasc Surg 2003, I 26(2):504-9. discussion 509-10.

12. Muthurangu V, Taylor AM, Hegde SR, Johnson R, Tulloh R, Simpson JM, Qureshi S, Rosenthal E, Baker E, Anderson D, Razavi R: Cardiac magnetic resonance imaging after stage I Norwood operation for hypoplastic left heart syndrome. Circulation 2005, I I 2(2 I):3256-63.
13. Hatle L, Angelsen B: Physics of Blood Flow - Doppler Ultrasound in Cardiology 1985.

14. Chapman CB, Baker O, Reynolds J, Bonte FJ: Use of biplane cinefluorography for measurement of ventricular volume. Circulation 1958, I 8(6): I 105-17.

15. Fraisse A, Colan SD, Jonas RA, Gauvreau K, Geva T: Accuracy of echocardiography for detection of aortic arch obstruction after stage I Norwood procedure. Am Heart J 1998, I35(2 Pt I):230-6.

16. Tworetzky W, McElhinney DB, Burch GH, Teitel DF, Moore P: Balloon arterioplasty of recurrent coarctation after the modified Norwood procedure in infants. Catheter Cardiovasc Interv 2000, 50( I):54-8

17. Zeltser I, Menteer J, Gaynor JW, Spray TL, Clark BJ, Kreutzer J, Rome J): Impact of re-coarctation following the Norwood operation on survival in the balloon angioplasty era. J Am Coll Cardiol 2005, 45( I I): I844-8.

18. Lim DS, Peeler BB, Matherne GP, Kron IL, Gutgesell HP: Risk-stratified approach to hybrid transcatheter-surgical palliation of hypoplastic left heart syndrome. Pediatr Cardiol 2006, 27(I):91-5.

19. Alboliras ET, Chin AJ, Barber G, Helton JG, Pigott JD, Norwood WI: Pulmonary artery configuration after palliative operations for hypoplastic left heart syndrome. J Thorac Cardiovasc Surg 1989, 97(6):878-85.

20. Eichhorn JG, Fink C, Delorme S, Hagl S, Kauczor HU, Ulmer HE: Magnetic resonance blood flow measurements in the followup of pediatric patients with aortic coarctation - a re-evaluation. Int J Cardiol 2006, I I 3(3):29|-8.

21. Bartram U, Grunenfelder J, Van Praagh R: Causes of death after the modified Norwood procedure: a study of 122 postmortem cases. Ann Thorac Surg 1997, 64(6): I795-802.

22. McGuirk SP, Griselli M, Stumper OF, Rumball EM, Miller P, Dhillon R, de Giovanni JV, Wright JG, Barron DJ, Brawn WJ: Staged surgical management of hypoplastic left heart syndrome: a single institution I 2 year experience. Heart 2006, 92(3):364-70.

23. Tweddell JS, Hoffman GM, Mussatto KA, Fedderly RT, Berger S, Jaquiss RD, Ghanayem NS, Frisbee SJ, Litwin SB: Improved survival of patients undergoing palliation of hypoplastic left heart syndrome: lessons learned from II5 consecutive patients. Circulation 2002, I 06( 12 Suppl I):182-9.

24. Denslow S, Wiles HB, McKellar LF, Wright NA, Gillette PC: Right ventricular volume estimation with an ellipsoidal shell model and two-plane magnetic resonance imaging. Am Heart J 1995 , I 29(4):782-90.

25. Denslow S, Wiles HB, McKellar LF, Wright NA, Gillette PC: Right ventricular volume estimation using an ellipsoidal shell model and single-plane magnetic resonance imaging. Invest Radiol 1996, 3 I(I): I7-25.

26. Valsangiacomo Buchel ER, DiBernardo S, Bauersfeld U, Berger F: Contrast-enhanced magnetic resonance angiography of the great arteries in patients with congenital heart disease: an accurate tool for planning catheter-guided interventions. Int J Cardiovasc Imaging 2005, 2 I (2-3):3 I 3-22.

27. Nielsen JC, Powell AJ, Gauvreau K, Marcus EN, Prakash A, Geva T: Magnetic resonance imaging predictors of coarctation severity. Circulation 2005, I I I(5):622-8.

Publish with Bio Med Central and every scientist can read your work free of charge

"BioMed Central will be the most significant development for disseminating the results of biomedical research in our lifetime. "

Sir Paul Nurse, Cancer Research UK

Your research papers will be:

- available free of charge to the entire biomedical community

- peer reviewed and published immediately upon acceptance

- cited in PubMed and archived on PubMed Central

- yours - you keep the copyright 